\title{
Optimization of hot air drying process for tiger nut and analysis of fatty acid composition of tiger nut oil
}

\author{
$\mathrm{He} \mathrm{Li}^{1}$, Xiaoxiao Niu${ }^{1}$, Jiajun $\mathrm{Chai}^{1}$, Changle Guo ${ }^{1}$, Yihao Sun ${ }^{2}$, Jianhua $\mathrm{Li}^{3}$, Chunying $\mathrm{Li}^{2 *}$ \\ (1. College of Mechanical \& Electrical Engineering, Henan Agricultural University, Zhengzhou 450002, China; \\ 2. College of Food Science and Technology, Henan Agricultural University, Zhengzhou 450002, China; \\ 3. Xuchang City Branch of Henan Tobacco Company, Xuchang 461000, Henan, China)
}

\begin{abstract}
Hot air temperature, hot air humidity, and hot wind speed were selected as independent variables of quadratic orthogonal rotation combination test design through single factor test. Drying time, energy consumption, chromatism value, luminosity value, hardness, rehydration ratio, and other indexes of the product were used as the response value of the test. Response surface methodology (RSM) was used to analyze the effects of independent variables on the quality of tiger nut (Cyperus esculentus L.), and the process parameters were combined and optimized. The results show that the suitable technological conditions for hot air drying of tiger nut are as follows: hot air temperature of $63.15^{\circ} \mathrm{C}$, hot air humidity of $44.92 \%$, hot air wind speed of $2.48 \mathrm{~m} / \mathrm{s}$. Under these conditions, the product has the advantages of the short drying cycle, low energy consumption, good color and luster, low hardness and good rehydration performance. The fatty acid composition and content of tiger nut oil were determined by gas chromatography. The fatty acid composition and content of tiger nut oil were compared with those of soybean oil, olive oil, rapeseed oil and sesame oil, the results show that among the saturated fatty acids in tiger nut oil, palm oil had the highest content of $11.172 \%$, which was between soybean oil and olive oil. The main composition of unsaturated fatty acids in tiger nut oil is oleic acid, with a content of $77.605 \%$, which is 3.6 times higher than that of soybean oil, and even higher than that of olive oil.
\end{abstract}

Keywords: process optimization, tiger nut, hot air drying, fatty acid composition, oil response surface method DOI: $10.25165 /$ j.ijabe.20211406.6646

Citation: Li H, Niu X X, Chai J J, Guo C L, Sun Y H, Li J H, et al. Optimization of hot air drying process for tiger nut and analysis of fatty acid composition of tiger nut oil. Int J Agric \& Biol Eng, 2021; 14(6): 228-236.

\section{Introduction}

Known as the "Food of God", the tiger nut (Cyperus esculentus L.) is a herb native to Africa and Mediterranean countries $^{[1-4]}$. The nutritional value of tiger nuts is very high. Its protein is three times that of milk. It is rich in 17 kinds of amino acids. The content of linoleic acid and linolenic acid is higher than that of olive oil. Its natural vitamin $\mathrm{E}$ is more than $56 \%$. Its high manganese content can regulate insulin and make the body achieve balance. Tiger nuts also have the effects of lowering blood pressure, lowering blood fats and cholesterol, and strengthening the resistance of capillaries ${ }^{[5]}$. At present, China's planting area is small ${ }^{[6-8]}$. If China's sandy land is properly used for tiger nut cultivation, it can reduce about 20 million $t$ of soybean

\section{Received date: 2021-04-01 Accepted date: 2021-08-29}

Biographies: $\mathbf{H e ~} \mathbf{L i}, \mathrm{PhD}$, Professor, research interest: design and control of agricultural equipment, Email: chungbuk@163.com; Xiaoxiao Niu, MS candidate, research interest: agricultural equipment and control system, Email: 15637863325@163.com; Jiajun Chai, MS candidate, research interest: agricultural equipment and control system, Email: 2118728973@qq.com; Changle Guo, MS candidate, research interest: agricultural equipment and control system, Email: 1943235984@qq.com; Yihao Sun, MS candidate, research interest: study on changes and functions of food nutritional components in food processing, Email: m18538738006@163.com; Jianhua Li, BS, Agronomist, research interest: research on Tobacco Technology Popularization, Email: xcwdqljh@sina.com; Chunying Li, PhD, Professor, research interest: study on changes and functions of food nutritional components in food processing, Email: 1789948048@qq.com.

*Corresponding author: Chunying $\mathbf{L i}, \mathrm{PhD}$, Professor, research interest: study on changes and functions of food nutritional components in food processing. College of Food Science and Technology, Henan Agricultural University, Zhengzhou 450002, China. Tel: +86-18939258535, Email: 1789948048@qq.com. imports and increase China's self-sufficiency rate of edible oil by 20 percentage points ${ }^{[9]}$. This can fundamentally reverse the situation of China's tight supply of edible oil raw materials and dependence on imports ${ }^{[10,11]}$. The comprehensive development of tiger nut industry has important strategic significance for the security of grain and oil in China ${ }^{[12-14]}$.

Because tiger nut itself is difficult to store, the drying technology of tiger nut has been studied in different degrees around the world researchers. It was found that the drying rate and effective diffusion coefficient of tiger nuts increased with the increase of drying temperature, the water diffusion activation energy of tiger nuts was lower, and the energy consumption of tiger nuts drying was less ${ }^{[15]}$. Some scholars adopted a completely randomized experimental design to study the effects of water content on physical properties such as sphericity, porosity, angle of repose and friction coefficient of black tiger nut varieties ${ }^{[16]}$. The thermal behavior of tiger nuts during drying was studied, and the relationship between the thermal properties (bulk density, specific surface area, thermal conductivity, thermal diffusion coefficient and specific heat capacity, etc.) and water content of tiger nuts was found ${ }^{[17]}$. In China, in order to prolong the shelf life of peeled tiger nuts, the surface of peeled tiger nuts was evenly coated with amino acid aqueous solution, and Maillard reaction between amino acids and reducing sugars on the surface of tiger nuts was used to inhibit ethanol fermentation, delay lipid oxidation, and effectively prolong the shelf life of peeling tiger nuts ${ }^{[18]}$. However, the drying process of tiger nuts also affects the quality of the product, but there are few systematic studies on the effects of different drying conditions on the quality of tiger nuts.

Therefore, this experiment used tiger nuts as raw materials. 
By changing the temperature, humidity, and wind speed in the drying process, the effects of different drying conditions on the quality of tiger nuts were analyzed from the aspects of drying time, energy consumption, value of chromatism value, luminosity value, hardness, and rehydration ratio, etc. So as to provide a theoretical reference for the industrialized production of tiger nut dry products. At present, gas chromatography is the most widely used method for the analysis of fatty acid composition ${ }^{[19,20]}$. It has the characteristics of short analysis time, good separation effect, low detection limit, and high sensitivity ${ }^{[21,22]}$. At present, there are few studies on the fatty acid composition and content of tiger nut oil. Therefore, the fatty acid composition and content of tiger nut oil were determined by gas chromatography and compared with those of soybean oil, olive oil, rapeseed oil and sesame oil, the purpose of this study was to provide a theoretical basis for the quality identification, safety development and nutritional evaluation of the Chinese Tiger nut oil.

\section{Materials and methods}

\subsection{Materials}

Tiger nuts were planted and harvested at a farm located at Shangqiu City, Henan Province, China, in November 2020. Tiger nuts have an elliptical shape, the average weight of tiger nuts was $1.125 \mathrm{~g}$, the average geometric diameter of tiger nuts was $10.988 \mathrm{~mm}$, the density of tiger nuts was $1.17 \mathrm{~g} / \mathrm{cm}^{3}$, the wet base moisture content of tiger nuts was $44 \%\left(105^{\circ} \mathrm{C}\right.$ constant weight method), and the angle of repose of tiger nuts was $32.91^{\circ}$. Tiger nuts were water-washed to remove dust and impurities. The cleaned tiger nuts were dried in the air to remove the moisture on the surface. The tiger nuts were sealed with polyethylene plastic and stored at $(4 \pm 1)^{\circ} \mathrm{C}$.

\subsection{Instrument and equipment}

JK-KB1700 thin-layer drying testbed (National Engineering Laboratory of Grain Storage and Transportation, Changchun, Jilin, China), the wind temperature range is $20^{\circ} \mathrm{C}-100^{\circ} \mathrm{C}\left( \pm 1^{\circ} \mathrm{C}\right)$, the humidity range is $20 \%-80 \% \mathrm{RH}( \pm 4 \% \mathrm{RH})$, and the wind speed range is $1.0-3.2 \mathrm{~m} / \mathrm{s}$. JA3003N type electronic analytical balance (Shanghai Youke Instrument Co., Ltd, Shanghai, China), the weighing range is $0-310 \mathrm{~g}$ and the reading accuracy is $0.001 \mathrm{~g}$. Model 101-00A electric heating blast drying oven (Tianjin Saidelis Experimental Analysis Instrument Factory, Tianjin, China), the temperature control range is $20^{\circ} \mathrm{C}-300^{\circ} \mathrm{C}\left( \pm 1^{\circ} \mathrm{C}\right)$. TESTO $410-2$ handheld anemometer (Detu Instrument International Trading Co.,

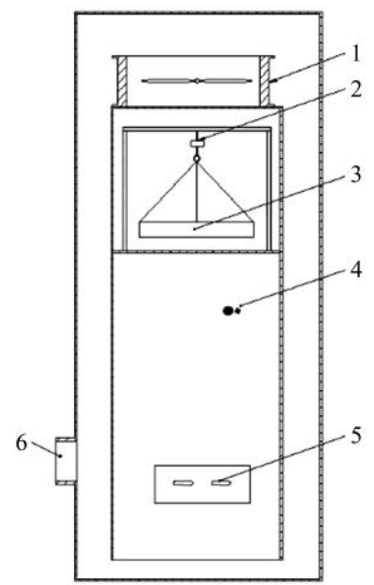

1. Circulating fan 2. Tension sensor 3. Material tray 4. Temperature and humidity sensor 5. Electric heating device 6. Dehumidification valve

Figure 1 Schematic diagram of JK-KB1700 thin layer drying testbed
Ltd, Baden-Wurttemberg, Germany), the measurement range is $0.4-20 \mathrm{~m} / \mathrm{s} \quad( \pm 0.2 \mathrm{~m} / \mathrm{s})$. LK1048U multi-channel temperature detector (Changzhou blue light Electronics Co., Ltd., Changzhou, Jiangsu, China), The measurement range is $-100^{\circ} \mathrm{C}-400^{\circ} \mathrm{C}\left( \pm 1^{\circ} \mathrm{C}\right)$. WR-10 precision value of chromatism instrument (Shenzhen Weifu Photoelectric Technology Co., Ltd, Shenzhen, China), repeatability $\Delta E<0.08$. TMS-PRO type texture instrument (American FTC company, Starling City, Virginia, USA), HDP/KS5 probe was used, the test parameters were set as induction force $0.5 \mathrm{~N}$, initial force $0.1 \mathrm{~N}$, test speed $60 \mathrm{~mm} / \mathrm{s}$, and the detection accuracy was $0.015 \%$. GC-2010 gas chromatograph (FID detector), (Shimadzu Co., Ltd., Japan), the scanning speed over $10000 \mathrm{amu} / \mathrm{s}$.

\subsection{Determination of moisture content}

According to the "Determination of Moisture in Food" direct drying method in GB5009.3-2016 $6^{[23]}$, the tiger nuts were dried in an oven at $105^{\circ} \mathrm{C}$ to a constant mass ${ }^{[24]}$. The moisture content of tiger nut was measured by Equation (1).

$$
M_{0}=\frac{W_{2}-W_{1}}{W_{1}-W_{0}} \times 100 \%
$$

where, $M_{0}$ is the moisture content of tiger nut, $\% ; W_{0}$ is the weight of empty aluminum boxes, $\mathrm{g}$; $W_{1}$ is the total weight of materials and aluminum boxes before drying, g; $W_{2}$ is the total weight of materials and aluminum boxes after drying, $g$.

\subsection{Energy consumption of drying}

Drying energy consumption ${ }^{[25]}$ is the main index reflecting energy consumption level and energy saving and consumption reduction. The reduction of energy consumption can effectively save the drying cost of tiger nuts, and it is one of the important evaluation indexes of the whole drying process. Drying energy consumption (Equation (2)) is defined in this study as the energy consumed to remove $200 \mathrm{~g}$ of water from tiger nuts.

$$
Q=P \cdot t
$$

where, $Q$ is the drying energy consumption of materials, $\mathrm{kW} \cdot \mathrm{h} ; P$ is the output power of thin-layer drying testbed, $\mathrm{kW} ; t$ is the drying time, h.

\subsection{Determination of color and luster}

The $a, b$, and $L$ values of tiger nuts before and after drying were measured and the corresponding $\Delta E$ values (Equation (3)) were calculated using WR-10 precision colorimeter ${ }^{[26]}$.

$$
\Delta E=\sqrt{\left(L-L_{0}\right)^{2}+\left(a-a_{0}\right)^{2}+\left(b-b_{0}\right)^{2}}
$$

where, $L$ and $L_{0}$ are respectively the luminosity of the sample before and after drying; $a$ and $a_{0}$ are respectively the red-green degree of the sample before and after drying; $b$ and $b_{0}$ are respectively the yellow and blue degrees of the samples before and after drying.

\subsection{Determination of hardness}

After drying, 20 tiger nuts were selected from each group, and TPA test was performed using a texture analyzer ${ }^{[27]}$. HDP/KS5 probe was used, and the test parameter was set as the induction force $0.5 \mathrm{~N}$. The initial force was $0.1 \mathrm{~N}$, the test rate was $60 \mathrm{~mm} / \mathrm{s}$, and the compression deformation was $50 \%$.

\subsection{Determination of rehydration ratio}

$2.0 \mathrm{~g}$ of the dried sample of tiger nuts was taken into a $100 \mathrm{~mL}$ container, $50 \mathrm{~mL}$ of distilled water was added, soaked in a constant temperature water bath at $60^{\circ} \mathrm{C}$, and then taken out after $5 \mathrm{~h}$. The surface moisture was dried with filter paper and weighed ${ }^{[28]}$. The rehydration ratio of the sample was calculated (Equation (4)).

$$
\mathrm{RR}=\frac{W_{w}}{W_{d}}
$$

where, $\mathrm{RR}$ is the rehydration ratio; $W_{w}$ is the weight of tiger nuts 
after rehydration, g; $W_{d}$ is the weight of tiger nuts before rehydration, $\mathrm{g}$.

\subsection{Determination of fatty acid composition and content}

\subsubsection{Sample preparation}

The dried tiger nut was taken as the sample, ground and mixed. A certain sample was taken into a conical flask with stopper. 2-3 times of the sample volume of petroleum ether was added into the conical flask, shaken well to make the sample and petroleum ether fully mixed. The solution was stood for more than $12 \mathrm{~h}$, then, filtered through a funnel filled with anhydrous sodium sulfate. The filtrate was taken in a water bath pot lower than $40^{\circ} \mathrm{C}$. The petroleum ether was dried with a rotary evaporator at $40^{\circ} \mathrm{C}$. Then the residue was taken out for standby.

\subsubsection{Methyl esterification of fat}

Refer to GB 5009.168-2016 determination of fatty acids in food $^{[29]}$. $25 \mu \mathrm{L}$ sample was taken, put into a measuring cylinder with a plug. $1.5 \mathrm{~mL}$ of $2 \%$ sodium hydroxide methanol solution was added to the measuring cylinder. The solution was taken in a $70^{\circ} \mathrm{C}-80^{\circ} \mathrm{C}$ water bath pot for $5 \mathrm{~min}$. After taking out and shaking, adding $2 \mathrm{~mL}$ boron trifluoride solution, the solution was immediately put into a $70^{\circ} \mathrm{C}-80^{\circ} \mathrm{C}$ water bath for $5 \mathrm{~min}$, and cooled to $30^{\circ} \mathrm{C}-40^{\circ} \mathrm{C}$. $1 \mathrm{~mL} \mathrm{n}$-hexane was added to it. After shaking for $0.5 \mathrm{~min}, 5 \mathrm{~mL}$ saturated sodium chloride solution was added to it. The solution was shaken evenly and allowed to stand for $1 \mathrm{~min}$. After the solution was layered, the supernatant was absorbed into the centrifuge tube with a small amount of sodium thiosulfate, and placed in the refrigerator at $-20^{\circ} \mathrm{C}$ for standby. In order to compare with tiger nut oil, soybean oil, olive oil, rapeseed oil and sesame oil were sampled and methylated.

\subsubsection{Chromatographic conditions}

FID detector and DB-Wax capillary column $(30 \mathrm{~m} \times 0.25 \mathrm{~mm}$ id $\times 0.50 \mu \mathrm{m}$ ) were used. The temperature rising procedure was as follows: the starting temperature was $50^{\circ} \mathrm{C}$, lasted for $1 \mathrm{~min}$, and the temperature rose to $200^{\circ} \mathrm{C}$ at the speed of $20^{\circ} \mathrm{C} / \mathrm{min}$, then rose to $230^{\circ} \mathrm{C}$ at the speed of $3^{\circ} \mathrm{C} / \mathrm{min}$, and the temperature was kept for $16 \mathrm{~min}$. The injection port temperature was $250^{\circ} \mathrm{C}$. The injection quantity was $1 \mu \mathrm{L}$. The split ratio was 1:50. The carrier gas was nitrogen, the purge flow rate was $3 \mathrm{~mL} / \mathrm{min}$, and the tail purge flow rate was $30 \mathrm{~mL} / \mathrm{min}$; The flow rate of hydrogen was $30 \mathrm{~mL} / \mathrm{min}$; The air flow was $30 \mathrm{~mL} / \mathrm{min}$. Each group of sample determinations was repeated 3 times.

\subsection{Single-factor experimental design}

According to Reference [34], three factors, namely hot air temperature, hot air humidity, and hot wind speed, were selected as single factors, and five levels were tested by changing one factor each time. The experiments were conducted to investigate the influence of each factor on the drying of tiger nuts. Each experiment was repeated 3 times. The experimental design is listed in Table 1.

Table 1 Single factor test factor and level of hot air drying of tiger nuts

\begin{tabular}{lccccc}
\hline \multicolumn{1}{c}{ Factor } & \multicolumn{5}{c}{ Level } \\
\cline { 3 - 7 } Temperature $/{ }^{\circ} \mathrm{C}$ & 35 & 45 & 55 & 65 & 75 \\
Humidness $/ \%$ & 35 & 40 & 45 & 50 & 55 \\
Wind speed $/ \mathrm{m} \cdot \mathrm{s}^{-1}$ & 1 & 1.6 & 2.1 & 2.7 & 3.2 \\
\hline
\end{tabular}

According to the test scheme, the washed and drained tiger nuts were evenly tiled on a $250 \mathrm{~mm}$ diameter mesh tray (Figure 2), and then the tray was placed in a thin-layer drying testbed. The loading amount of mesh trays in the three groups of parallel tests was all $200 \mathrm{~g}$. The trays were placed in the mesh trays when the drying conditions of the thin-layer drying test bed met the test requirements. The test bench recorded the weight of tiger nuts at regular intervals until the moisture content of tiger nuts was reduced to $10 \%$ of the national standard safe storage moisture content. Remove the tiger nuts and seal and label them.

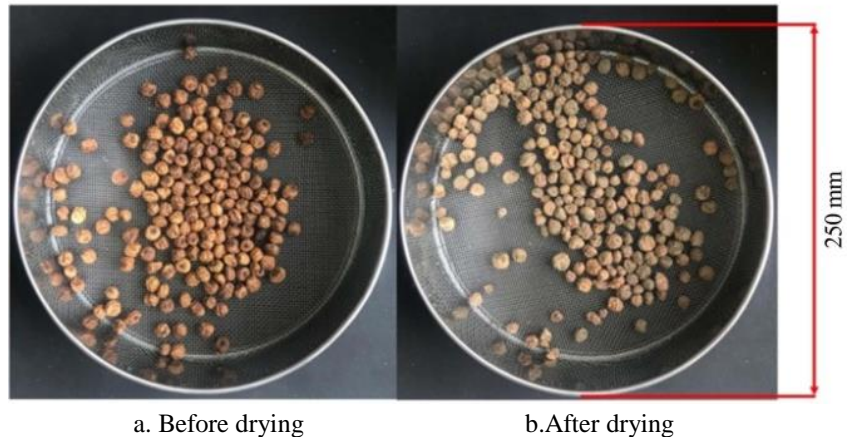

Figure 2 Drying test of tiger nuts

\subsection{Regression orthogonal experimental design}

With hot air temperature, hot air humidity, and hot wind speed as independent variables, and drying time, energy consumption, value of chromatism, luminosity value, hardness, and rehydration ratio as dependent variables, quadratic regression orthogonal rotation combination test was conducted. The level setting and coding table of each factor are listed in Table 2.

Table 2 Factor level coding of hot air drying of tiger nuts

\begin{tabular}{cccc}
\hline Code value & Temperature $/{ }^{\circ} \mathrm{C}$ & Humidness $/ \%$ & Wind speed $/ \mathrm{m} \cdot \mathrm{s}^{-1}$ \\
\hline+1.682 & 70.00 & 51.00 & 3.20 \\
+1 & 63.92 & 48.57 & 2.75 \\
0 & 55.00 & 45.00 & 2.10 \\
-1 & 46.08 & 41.43 & 1.45 \\
-1.682 & 40.00 & 39.00 & 1.00 \\
\hline
\end{tabular}

\section{Data analysis}

\subsection{Single factor test results of hot air temperature}

It can be seen from Figure 3a that when the humidity of hot air is $45 \%$ and the wind speed of hot air is $2.1 \mathrm{~m} / \mathrm{s}$, the drying time and energy consumption of tiger nuts decrease gradually with the increase of hot air temperature. When the hot air passes over the wet tiger nut surface, there is a driving force of heat transfer (temperature difference) between the air and the tiger nut ${ }^{[30]}$. As shown in Equation (5), an increase in the temperature of the hot air results in an increase in the heat transfer driving force between the air and the tiger nut. The heat from the air was transferred to the tiger nut, and the transfer of heat between the air and the tiger nut was accelerated. The water inside the tiger nut was vaporized faster, and the drying time was shorter.

$$
Q=h_{H} A\left(T_{\infty}-T_{w}\right)
$$

where, $h_{H}$ is the surface convective heat transfer coefficient, $\mathrm{kg} /\left(\mathrm{m}^{2} \cdot \mathrm{K}\right) ; Q$ is the heat flow, $\mathrm{W} ; A$ is the effective heat transfer surface area, $\mathrm{m}^{2} ; T_{w}$ is the temperature of the material surface, $\mathrm{K}$; $T_{\infty}$ is the air main flow temperature, $\mathrm{K}$.

The drying energy consumption $Q$ of tiger nut depends on the heating power $P$ and drying time $T$. Heating power $P$ and drying time $T$ at different hot air temperatures are shown in Figure $3 \mathrm{~b}$. When the hot air temperature is between $35^{\circ} \mathrm{C}-75^{\circ} \mathrm{C}$, the heating power has little difference. The drying energy consumption of tiger nuts is mainly controlled by its drying time, that is, the longer the drying time is, the higher the drying energy consumption of tiger nuts. 


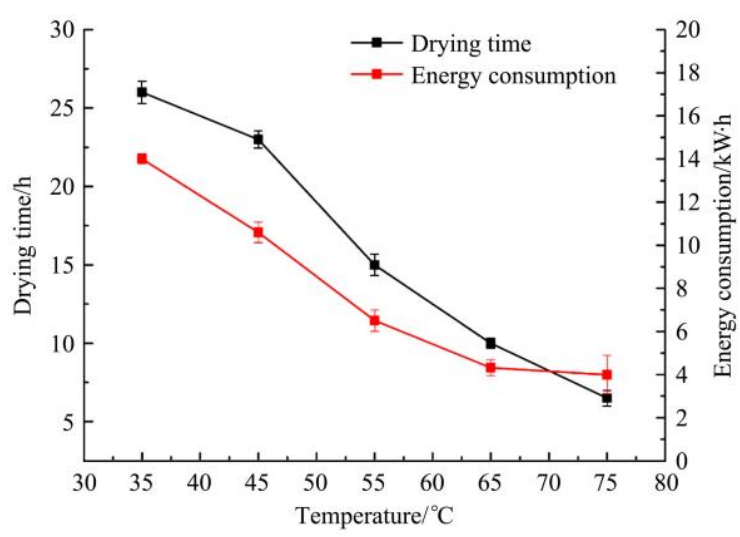

a. Influence of hot air temperature on drying time and energy consumption

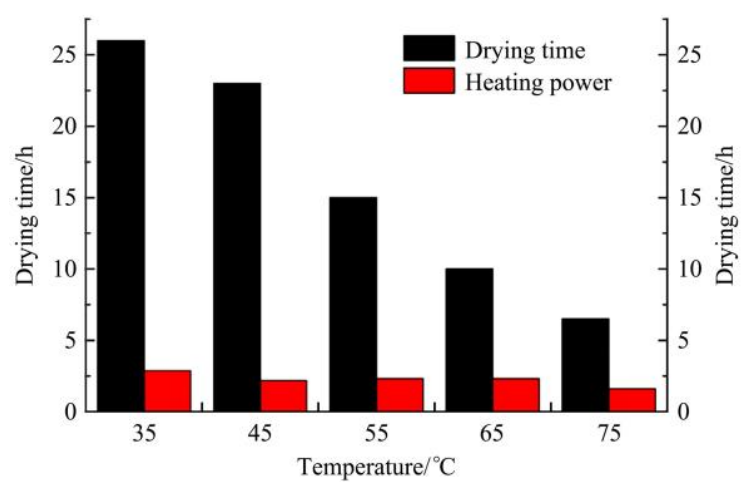

b. Drying time and heating power under different hot air temperatures

Figure 3 Effects of hot air temperature on drying time and energy consumption

It can be seen from Figure 4 that, when the humidity of hot air is $45 \%$ and the wind speed of hot air is $2.1 \mathrm{~m} / \mathrm{s}$, the luminosity value of tiger nuts surface decreases gradually with the increase of hot air temperature. When the hot air temperature was $35^{\circ} \mathrm{C}$ and $75^{\circ} \mathrm{C}$, the luminosity $L$ of tiger nut surface decreased to 9.61 and 2.10 , respectively. The results showed that the luminosity of dried tiger nuts at high temperatures was lower than that of dried tiger nuts at low temperatures. The essence of the change in the surface color of tiger nuts is the result of a comprehensive reflection of the substances contained in tiger nuts ${ }^{[31]}$. The relationship between color parameters and the intrinsic quality of materials was studied. It was found that the change of luminosity value $L$ was significantly negatively correlated with the content of pigments and $\operatorname{starch}^{[32]}$. The loss of pigment and starch content at high temperatures resulted in the lower surface $L$ value of the dried tiger nuts.

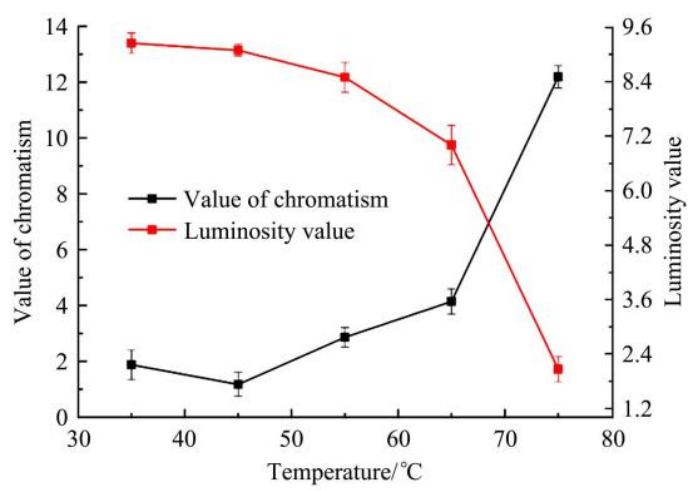

Figure 4 Influence of hot air temperature on value of chromatism and luminosity value

It can be seen from Figure 4 that when tiger nuts were dried at $35^{\circ} \mathrm{C}-55^{\circ} \mathrm{C}$, the growth rate of value of chromatism $\Delta E$ showed a trend of the first decreasing and then increasing, and $\Delta E$ showed a trend of rapid increase when they were dried at high temperature $\left(65^{\circ} \mathrm{C}\right.$ and $\left.75^{\circ} \mathrm{C}\right)$. As a color parameter, $\Delta E$ is widely used to describe the color changes of agricultural products during processing or storage. When $\Delta E>2$ is present, the change of color can be easily captured by vision ${ }^{[33]}$. When the hot air temperature exceeds $55^{\circ} \mathrm{C}$, the values of chromatism changes are more obvious.

It can be seen from Figure 5 that when the humidity of the hot air is $45 \%$ and the wind speed of the hot air is $2.1 \mathrm{~m} / \mathrm{s}$, the hardness of tiger nuts first increases and then decreases with the increase of the hot air temperature at low temperature $\left(35^{\circ} \mathrm{C}-55^{\circ} \mathrm{C}\right)$. When the hot air temperature exceeds $55^{\circ} \mathrm{C}$, the hardness of tiger nuts gradually increases with the increase of the hot air temperature. This is because at low temperature, when the temperature of hot air rises, the water on the surface of tiger nuts will vaporize faster, and the internal water cannot migrate to the surface in time, thus forming a dry hard film on the surface of tiger nuts and increasing the hardness ${ }^{[34]}$. With the further increase of hot air temperature, the structure and intermolecular force of protein and fat in tiger nuts were changed, which led to the decrease of the hardness of tiger nuts. Under high temperature conditions $\left(65^{\circ} \mathrm{C}\right.$ and $\left.75^{\circ} \mathrm{C}\right)$, the increase of hot air temperature will accelerate the mass transfer rate of tiger nut and destroy the microstructure of peanut, and the hardness of tiger nut will increase ${ }^{[35]}$.

It can be seen from Figure 5 that the rehydration ratio of tiger nut decreased with the increase of hot air temperature. The rehydration properties of tiger nuts are related to the changes in tissue structure and chemical composition caused by dryness. The relationship between hot air temperature and rehydration of materials was studied. It was found that the higher the hot air temperature was, the faster the water loss rate of materials in the initial drying process was, and the greater the volume shrinkage of dry products was. The high temperature would reduce the ability to restore the original state of dry products due to the serious damage of the cell tissue ${ }^{[36]}$. Therefore, the higher the temperature of hot air is, the worse the water rehydration of tiger nuts.

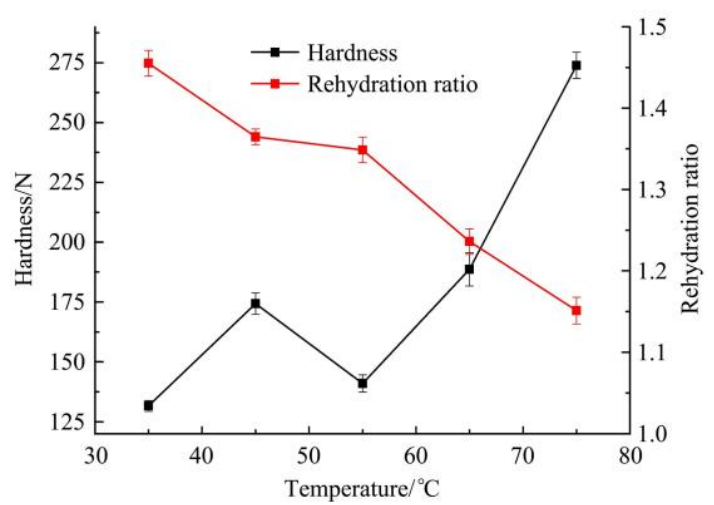

Figure 5 Influence of hot air temperature on hardness and rehydration ratio

\subsection{Single factor test results of hot air humidity}

It can be seen from Figure 6 that when the hot air temperature is $55^{\circ} \mathrm{C}$ and the hot air humidity is $2.1 \mathrm{~m} / \mathrm{s}$, the drying time of tiger nuts increases with the increase of the hot air humidity. In the process of hot air drying, the higher the relative humidity of the air, the higher the partial pressure of water vapor, the slower the surface evaporation rate, the slower the drying rate, and the longer the drying time. The drying time determines the drying energy consumption, and the hot air humidity increases, and the energy consumption increases. 


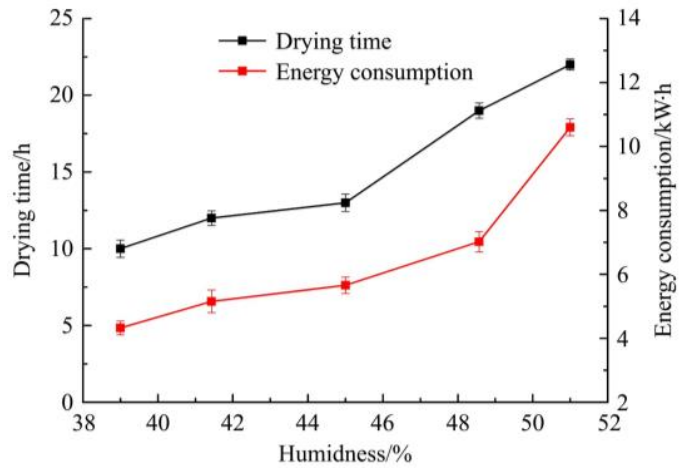

Figure 6 Influence of hot air humidity on drying time and energy consumption

Figure 7 shows that when the temperature of hot air is $55^{\circ} \mathrm{C}$ and the humidity of hot air is $2.1 \mathrm{~m} / \mathrm{s}$, the value of chromatism $\Delta E$ of tiger nuts decreases with the increase of the humidity of hot air. The main reason is that when the external relative humidity is high, the loss of pigments is less, and the change of values of chromatism on the surface of the dried tiger nut is small ${ }^{[34]}$. With the increase of the humidity of the hot air, its luminosity value $L$ shows an upward trend accordingly.

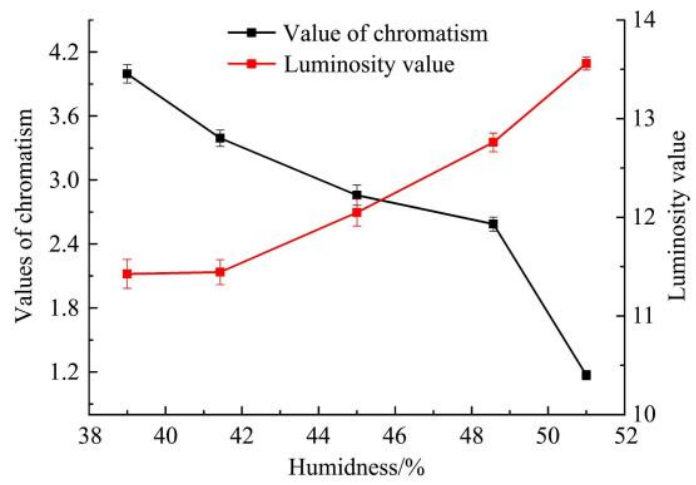

Figure 7 Influence of hot air humidity on values of chromatism and luminosity value

It can be seen from Figure 8 that when the hot air temperature is $55^{\circ} \mathrm{C}$ and the wind speed is $2.1 \mathrm{~m} / \mathrm{s}$, the rehydration ratio gradually increases with the increase of humidity value, while the hardness value gradually decreases with the increase of humidity value. This is because the shrinkage rate of tiger nuts decreases under high humidity environment, which leads to the increase of porosity, the improvement of rehydration ability, and the decrease of hardness value. At lower relative humidity, the rapid diffusion of water from the inside to the outside of the tiger nut would result in crusting, which would decrease the rehydration ability and increase the hardness of the tiger nut.

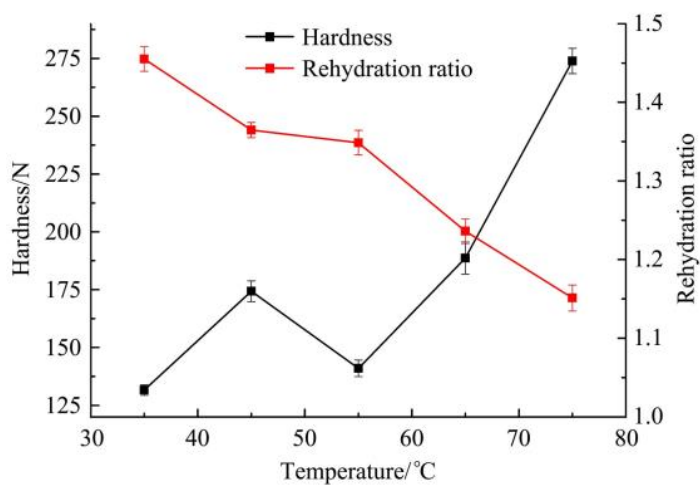

Figure 8 Influence of hot air humidity on hardness and rehydration ratio

\subsection{Single factor test results of hot air velocity}

As shown in Figure 9, when the temperature of hot air is $55^{\circ} \mathrm{C}$ and the humidity of hot air is $45 \%$, the higher the wind speed of hot air, the shorter the drying time of tiger nuts. The reason is that the faster the flow rate of air on the surface of tiger nut, the faster the evaporation rate of water on the surface of tiger nuts, and the shorter the drying time. As can be seen from Figure 9, there is little difference between drying time and heating power at different wind speeds, and the energy consumption depends on the product of drying time and heating power. When the wind speed is $1 \mathrm{~m} / \mathrm{s}$, the energy consumption is the lowest, and the energy consumption is $5.66 \mathrm{~kW} \cdot \mathrm{h}$.

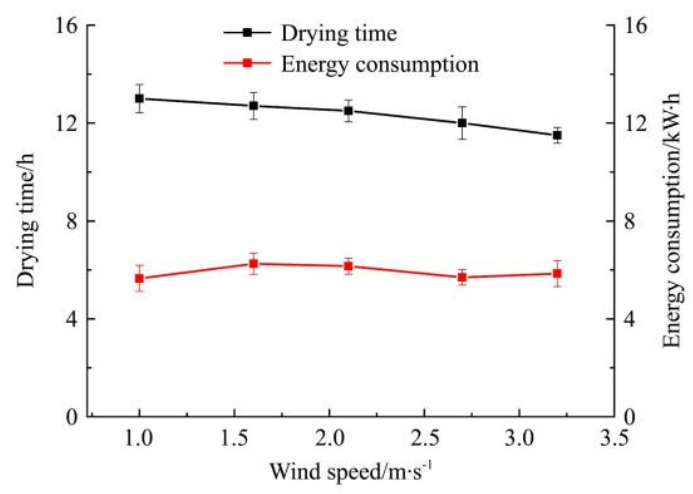

Figure 9 Influence of hot air speed on drying time and energy consumption

As shown in Figure 10, when the wind speed of hot air is $1.0-1.6 \mathrm{~m} / \mathrm{s}$, the value of chromatism $\Delta E$ and the luminosity value $L$ increase with the wind speed. When the wind speed of the hot air is $1.6-2.7 \mathrm{~m} / \mathrm{s}$, the value of chromatism $\Delta E$ and the luminosity value $L$ decrease with the wind speed; When the wind speed is $2.7-$ $3.2 \mathrm{~m} / \mathrm{s}$, the luminosity value $\Delta E$ increases with the wind speed, and the luminosity value $L$ decreases with the wind speed. The luminosity value $\Delta E$ reached the lowest when the wind speed was $1 \mathrm{~m} / \mathrm{s}$, and the luminosity value $L$ reached the highest when the wind speed was $1.6 \mathrm{~m} / \mathrm{s}$.

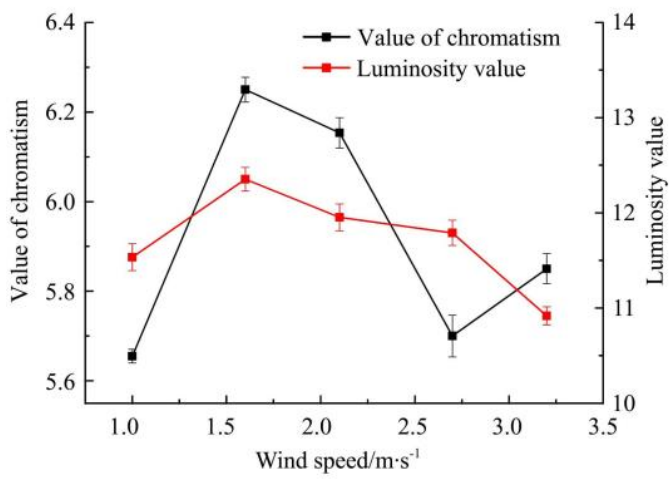

Figure 10 Influence of wind speed on value of chromatism and luminosity value

As shown in Figure 11, when the wind speed was 1.0-1.6 m/s, the hardness value of tiger nuts decreased. When the wind speed is $1.6-2.7 \mathrm{~m} / \mathrm{s}$, the hardness value increases; When the wind speed is $2.7-3.2 \mathrm{~m} / \mathrm{s}$, the hardness value decreases. When the wind speed is $1.6 \mathrm{~m} / \mathrm{s}$, the hardness value is the lowest. It was found that the hot air speed had little effect on the rehydration ratio of dried tiger nuts.

\subsection{Response surface test results}

On the basis of the single-factor test, the influence of various factors on the drying of tiger nuts was considered comprehensively. According to the Box-Benhnken test principle, the response surface 


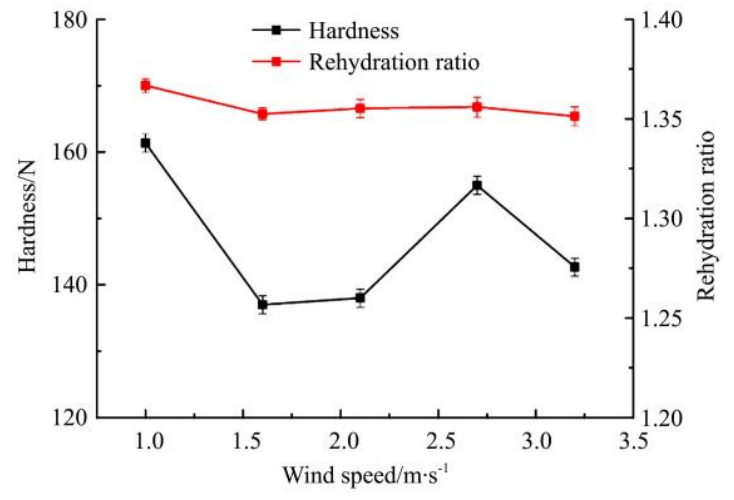

Figure 11 Influence of wind speed on hardness and rehydration ratio

analysis method was designed with three factors and five levels, including hot air temperature, hot air humidity and hot air speed, to determine the optimal drying conditions of tiger nuts. The results are listed in Table 3.

\subsection{Regression equation and parameter analysis}

Regressive analysis was conducted on the test results in Table 4 to obtain the multiple quadratic regression equation between hot air temperature $(A)$, hot air humidity $(B)$, hot air wind speed $(C)$ and the drying time, energy consumption, value of chromatism, luminosity value, hardness, and rehydration ratio of tiger nuts. The regression coefficient and variable analysis of this equation are shown in Table 4.

The determination coefficient $R^{2}$ of the equation is all above 0.85 , indicating that the equation has good fitting and small test error $^{[37]}$. According to the significance analysis of the equation, the temperature of hot air has a very significant effect on the drying indexes of tiger nuts. The humidity of hot air has a significant effect on drying time and energy consumption, but has no significant effect on other indexes. The hot air speed has significant influence on the value of chromatism and luminosity value, but has no significant influence on other indexes. The effect of three factors on the drying of tiger nuts was $A>B>C$.

Table 3 Response surface test design and results of hot air drying of tiger nuts

\begin{tabular}{|c|c|c|c|c|c|c|c|c|c|}
\hline No. & $A /{ }^{\circ} \mathrm{C}$ & $B / \%$ & $\mathrm{C} / \mathrm{m} \cdot \mathrm{s}^{-1}$ & $Y_{1} / \mathrm{h}$ & $Y_{2} / \mathrm{kW} \cdot \mathrm{h}$ & $Y_{3}$ & $Y_{4}$ & $Y_{5}$ & $Y_{6}$ \\
\hline 1 & -1 & -1 & -1 & 19 & 7.02 & 0.90121 & 0.268 & 134.336 & 1.47116 \\
\hline 2 & 1 & -1 & -1 & 8.5 & 4.697 & 4.5521 & 3.508 & 220.132 & 1.20414 \\
\hline 3 & -1 & 1 & -1 & 24.5 & 7.75 & 1.17211 & 0.528 & 156.52 & 1.45831 \\
\hline 4 & 1 & 1 & -1 & 10 & 4.3225 & 4.13844 & 3.17 & 188.66 & 1.23614 \\
\hline 5 & -1 & -1 & 1 & 22.5 & 7 & 0.92662 & 0.388 & 164.38 & 1.46829 \\
\hline 6 & 1 & -1 & 1 & 9 & 4.25 & 8.092 & 5.686 & 183.484 & 1.19114 \\
\hline 7 & -1 & 1 & 1 & 24.5 & 9.05 & 1.87259 & 0.826 & 131.568 & 1.45513 \\
\hline 8 & 1 & 1 & 1 & 11 & 6.15 & 4.65298 & 3.4 & 152.756 & 1.23303 \\
\hline 9 & -1.682 & 0 & 0 & 27 & 9.2 & 1.16644 & 0.206 & 130.536 & 1.4952 \\
\hline 10 & 1.682 & 0 & 0 & 6.5 & 3.99 & 12.191 & 8.332 & 273.836 & 1.15112 \\
\hline 11 & 0 & -1.682 & 0 & 13 & 6 & 3.99529 & 3.124 & 145.168 & 1.34113 \\
\hline 12 & 0 & 1.682 & 0 & 22 & 10.6 & 1.16922 & 0.99 & 174.292 & 1.36466 \\
\hline 13 & 0 & 0 & -1.682 & 13 & 5.655 & 1.534 & 0.954 & 161.332 & 1.36671 \\
\hline 14 & 0 & 0 & 1.682 & 11.5 & 5.85 & 4.118 & 2.86 & 142.676 & 1.35129 \\
\hline 15 & 0 & 0 & 0 & 10 & 4.45833 & 4.04935 & 2.408 & 158.36 & 1.35604 \\
\hline 16 & 0 & 0 & 0 & 12 & 6.85 & 3.392 & 2.324 & 139 & 1.35064 \\
\hline 17 & 0 & 0 & 0 & 14.5 & 6.5 & 2.85836 & 1.614 & 141 & 1.34867 \\
\hline 18 & 0 & 0 & 0 & 12.5 & 6.15385 & 1.95201 & 1.376 & 138 & 1.35528 \\
\hline 19 & 0 & 0 & 0 & 12 & 5.7 & 1.78931 & 1.138 & 155 & 1.35592 \\
\hline 20 & 0 & 0 & 0 & 12.5 & 6.25 & 2.354 & 1.072 & 137 & 1.35248 \\
\hline 21 & 0 & 0 & 0 & 15.5 & 7.70156 & 1.34189 & 0.998 & 136 & 1.35567 \\
\hline 22 & 0 & 0 & 0 & 12.5 & 5.95 & 2.58728 & 1.008 & 138 & 1.35592 \\
\hline 23 & 0 & 0 & 0 & 12 & 5.7 & 1.95201 & 1.376 & 142 & 1.35248 \\
\hline
\end{tabular}

Note: $A$ : Temperature; $B$ : Humidness; $C$ : Wind speed; $Y_{1}$ : Drying time; $Y_{2}$ : Energy consumption; $Y_{3}$ : Value of chromatism; $Y_{4}$ : Luminosity value; $Y_{5}$ : Hardness; $Y_{6}$ : Rehydration ratio, the same as below.

Table 4 Regression coefficient and variable analysis

\begin{tabular}{|c|c|c|c|c|c|c|}
\hline \multirow{2}{*}{$\begin{array}{l}\text { Coefficient of } \\
\text { regression equation }\end{array}$} & \multicolumn{6}{|c|}{$p$} \\
\hline & $Y_{1}$ & $Y_{2}$ & $Y_{3}$ & $Y_{4}$ & $Y_{5}$ & $Y_{6}$ \\
\hline$A$ & $<0.0001^{* * *}$ & $<0.0001^{* * *}$ & $<0.0001^{* *}$ & $<0.0001^{* * * *}$ & $<0.0001^{* * * *}$ & $<0.0001^{* * *}$ \\
\hline$B$ & $0.0006^{* * * *}$ & $0.0047^{* * *}$ & 0.0903 & 0.0521 & 0.7141 & 0.0563 \\
\hline$C$ & 0.6785 & 0.4368 & $0.0416^{*}$ & $0.0360^{*}$ & 0.1447 & 0.2701 \\
\hline$A^{2}$ & $0.0017^{* *}$ & 0.5584 & $0.0004^{* * *}$ & $0.0003^{* * *}$ & $0.0005^{* * *}$ & $0.0011^{* *}$ \\
\hline$C^{2}$ & 0.9322 & 0.9645 & 0.8608 & 0.8802 & 0.6632 & 0.7609 \\
\hline $\mathrm{AB}$ & $0.0017^{* *}$ & 0.0765 & $0.00249^{* *}$ & 0.1164 & 0.3093 & 0.1080 \\
\hline $\mathrm{AC}$ & $0.0405^{*}$ & 0.2201 & 0.3011 & $0.0532^{*}$ & $0.0053^{* *}$ & $0.3779^{*}$ \\
\hline $\mathrm{BC}$ & $0.0322^{*}$ & 0.5832 & 0.4606 & $<0.0001^{* * *}$ & 0.2858 & 0.7689 \\
\hline$R^{2}$ & 0.955180028 & 0.875748993 & 0.895757803 & 0.921228439 & 0.850886994 & 0.991069158 \\
\hline
\end{tabular}

Note: ${ }^{*}$ : Significantly affect, $p<0.05 ;{ }^{* *}:$ Very significant affect, $p<0.01 ;{ }^{* * *}:$ highly significant affect, $p<0.001$. 


\subsection{Interaction}

Table 4 shows that the interaction of hot air temperature and humidity had a significant effect on the drying time and value of chromatism of tiger nuts. The interaction of hot air temperature and wind speed had a significant effect on the hardness of tiger nuts. The interaction of hot air humidity and wind speed has a significant effect on the brightness value. Here, this study only analyzes the cases with significant interaction, other interactions are not considered. The interaction effect Equations (6) and (7) were obtained by observing the influence of the interaction of $A B$ on product $Y_{1}$ and $Y_{3}$ by fixing $C$ at level 0 . Then fixed $A$ as 0 , observe the interaction effect of $\mathrm{BC}$ on product $Y_{4}$, and got the interaction effect Equation (8). Finally, $B$ was fixed at level 0 to observe the influence of $A C$ interaction on product $Y_{5}$, and the interaction effect Equation (9) was obtained.

$$
Y_{1(A, B)}=316.219-2.108 A-11.148 B-0.016 A B+0.020 A^{2}+0.143 B^{2}
$$

$$
Y_{3(A, B)}=-34.220-0.631 A+1.900 B-0.020 A B+0.017 A^{2}-0.115 B^{2}
$$

$Y_{4(B, C)}=35.011-0.480 B+4.678 C-0.020 B C+0.006 B^{2}-0.063 C^{2}(8)$ $Y_{5(A, C)}=1289.582-20.426 A+61.526 C-1.664 A C+0.247 A^{2}+4.503 C^{2}$

According to Figure 12, when the wind speed of hot air was constant, the drying time of tiger nuts first decreased and then increased with the increase of humidity of hot air. When the temperature of hot air was low, this trend was more obvious. The drying time of tiger nuts decreased with the increase of hot air temperature. The drying time is the shortest when the temperature of hot air is the lowest and the humidity of hot air is the best.

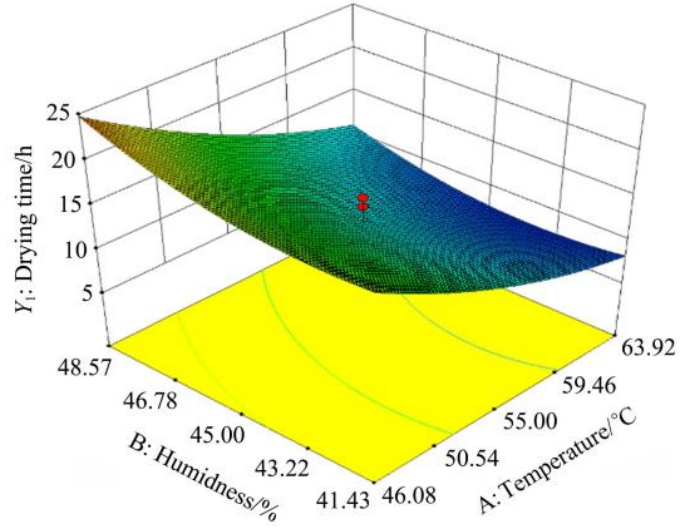

Figure 12 Impact of $\mathrm{AB}$ interaction on product $Y_{1}$

As can be seen from Figure 13, when the wind speed of the hot air is constant and the temperature of the hot air is high, the value of chromatism decreases with the increase of the humidity of the hot air. When the hot air humidity is low, the value of chromatism value increases rapidly with the hot air temperature rising. When the humidity of hot air is high, the value of chromatism value also increases with the increase of hot air temperature, and the increased speed slows down. When the temperature of the hot air reaches its lowest value and the humidity of the hot air reaches its highest value, the value of chromatism is the smallest.

As can be seen from Figure 14, when the temperature of hot air is constant and the wind speed of hot air is low, the surface luminosity value of tiger nut increases first and then decreases slowly with the increase of humidity. When the wind speed of hot air is high, the luminosity value decreases with the increase of humidity. When the humidity of hot air is low, the luminosity value increases with the increase of wind speed. When the humidity of hot air is high, the luminosity value decreases with the increase of wind speed. The luminosity value is maximized at the center. When the hot air humidity and the hot air wind speed were respectively optimal, the luminosity value of the tiger nut surface reached the maximum value.

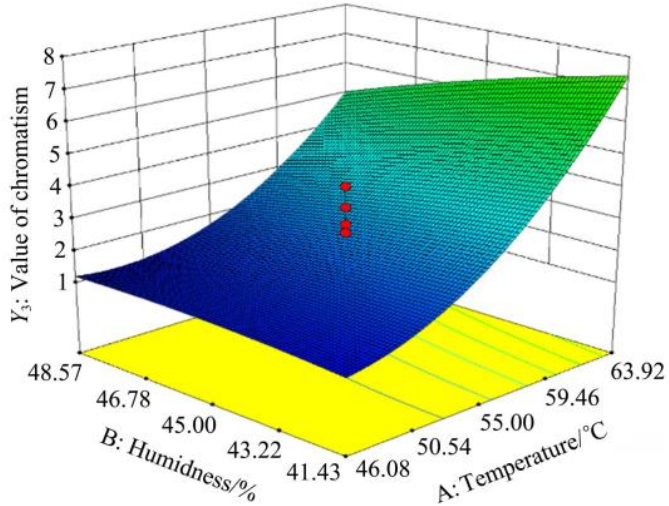

Figure 13 Impact of $\mathrm{AB}$ interaction on product $Y_{3}$

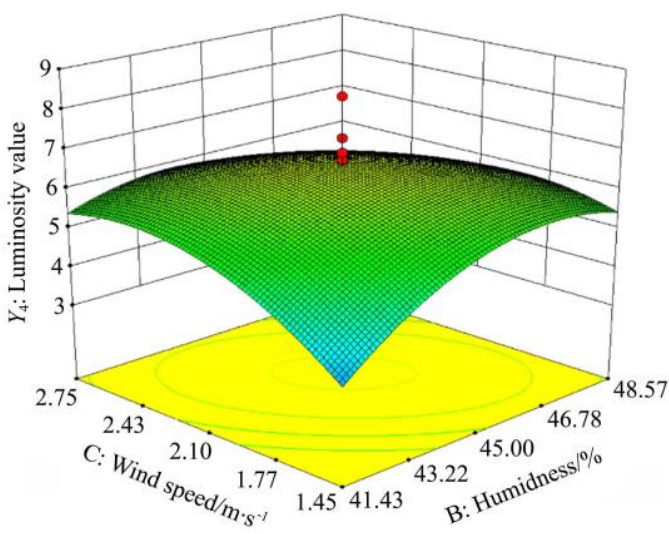

Figure 14 Influence of $\mathrm{BC}$ interaction on $Y_{4}$

As can be seen from Figure 15, when the humidity of hot air is constant and the temperature of hot air is low, the hardness of tiger nuts increases slowly with the increase of the speed of hot air. When the hot air temperature is higher, the hardness decreases with the increase of the hot air speed. The hardness increases with the increase of hot air temperature. When the temperature and speed of hot air are minimized, the hardness can be minimized.

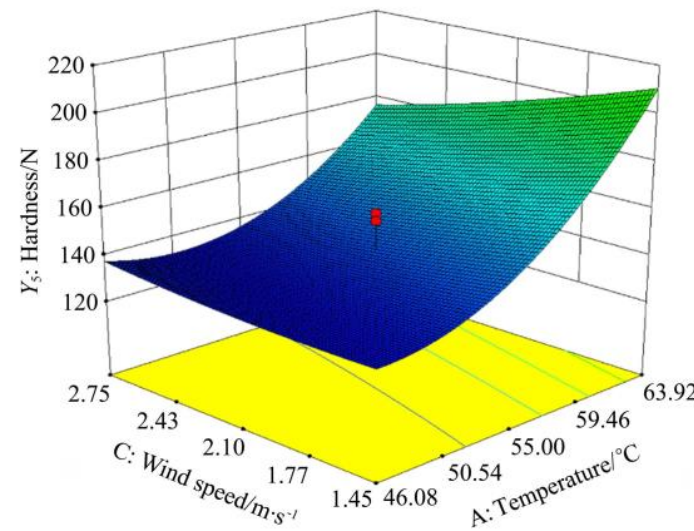

Figure 15 Influence of AC interaction on $Y_{5}$

\subsection{Process optimization}

The optimal combination of process parameters was found under the conditions of the shortest drying time, the lowest energy consumption, value of chromatism value, hardness value, luminosity value and the highest rehydration ratio. The optimal process parameters were obtained as hot air temperature $63.15^{\circ} \mathrm{C}$, 
hot air humidity $44.92 \%$, and hot air wind speed $2.48 \mathrm{~m} / \mathrm{s}$. Under these conditions, the hot air drying time was $8.05 \mathrm{~h}$, the energy consumption was $5.14 \mathrm{~kW} \cdot \mathrm{h}$, the value of chromatism value was 2.07 , the luminosity value was 6.98 , the hardness value was 177.47 N, and the rehydration ratio was 1.47 .

\subsection{Fatty acid composition and content of tiger nut oil}

The dried tiger nut was used as the sample under the optimal process parameters. The fat was extracted from the sample and methylated. The fatty acid composition and content of tiger nut oil were determined by gas chromatography. The relative content of fatty acids in tiger nut oil was calculated by normalization of peak area. The detection spectrum is shown in Figure 16.

The fatty acid composition and content of tiger nut oil and common vegetable oil were determined. The results are shown in Table 5. The results showed that among the saturated fatty acids in tiger nut oil, palm oil had the highest content (11.172\%), which was between soybean oil and olive oil. Tiger nut oil is rich in unsaturated fatty acids, and the content of unsaturated fatty acids in tiger nut oil is as high as $86.557 \%$, which is the highest in these vegetable oils. The main composition of unsaturated fatty acids in tiger nut oil is oleic acid. Oleic acid can reduce LDL-C and prevent arteriosclerosis, however, it does not reduce the level of HDL-C beneficial to the human body ${ }^{[38]}$. Oleic acid is called safe fatty acid in nutrition circle. The content of oleic acid is an important indicator to evaluate the quality of edible oil. The oleic acid content of tiger nut oil was $77.605 \%$ higher than that of other vegetable oils, which was 3.6 times higher than that of soybean oil, and even higher than that of olive oil. Tiger nut oil has high nutritional value, which is a kind of nutritional health oil with great development value.

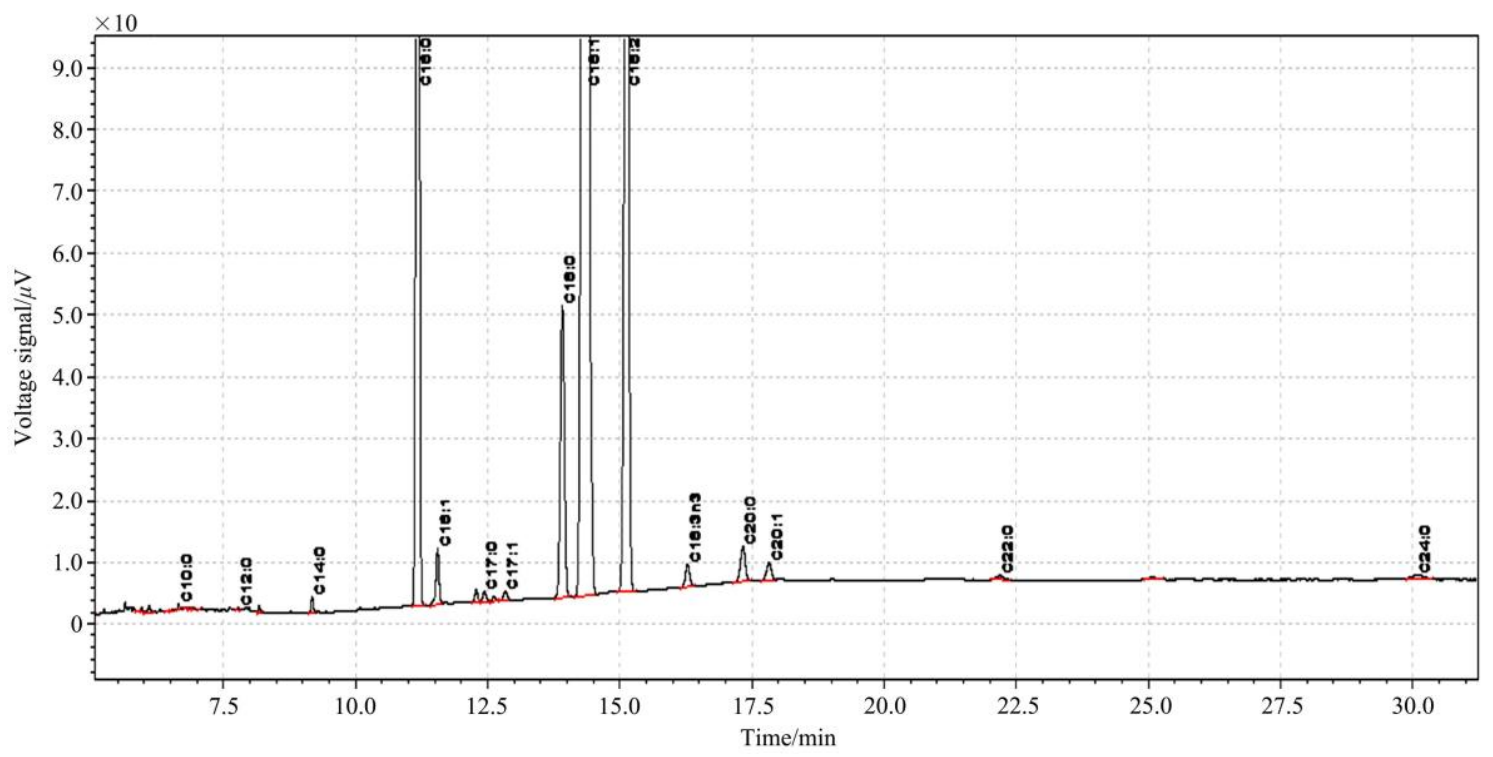

Figure 16 Chromatogram of fatty acid methyl ester in tiger nut oil

Table 5 Composition and content of fatty acids in tiger nut oil, soybean oil, olive oil, rapeseed oil and sesame oil

\begin{tabular}{|c|c|c|c|c|c|c|c|c|}
\hline \multirow{3}{*}{ Vegetable oil } & \multicolumn{4}{|c|}{ Saturated fatty acids } & \multicolumn{4}{|c|}{ Unsaturated fatty acids } \\
\hline & Myristic acid & Palmitic acid & Stearic acid & Arachidonic acid & Palmitoleic acid & Oleic acid & Linoleic acid & Linolenic acid \\
\hline & $\mathrm{C}_{14: 0}$ & $\mathrm{C}_{16: 0}$ & $\mathrm{C}_{18: 0}$ & $\mathrm{C}_{20: 0}$ & $\mathrm{C}_{16: 1}$ & $\mathrm{C}_{18: 1}$ & $\mathrm{C}_{18: 2}$ & $\mathrm{C}_{18: 3}$ \\
\hline Tiger nut oil & 0.059 & 11.172 & 1.127 & 0.301 & 0.442 & 77.605 & 8.511 & 0.059 \\
\hline soybean oil & 0.076 & 10.398 & 3.946 & 0.349 & 0.102 & 21.560 & 49.237 & 0.076 \\
\hline Olive oil & 0.015 & 12.937 & 2.429 & 0.369 & 1.266 & 67.960 & 8.829 & 0.015 \\
\hline Rapeseed oil & 0.061 & 4.139 & 1.950 & 0.675 & 0.248 & 52.552 & 16.496 & 0.061 \\
\hline Sesame oil & 0.018 & 9.169 & 5.642 & 0.598 & 0.150 & 40.017 & 43.212 & 0.018 \\
\hline
\end{tabular}

\section{Conclusions}

1) Single-factor experiment results showed that the hot air temperature has a significant effect on each index of tiger nut drying, the hot air humidity had significant effects on the drying time and energy consumption, the hot wind speed had a significant effect on the value of chromatism value and brightness, the influence of three factors on the tiger nuts dry sorting for the hot air temperature $>$ air humidity $>$ hot wind speed.

2) The results showed that the temperature, humidity, and wind speed of hot air had significant effects on the drying time, energy consumption, value of chromatism, luminosity value, hardness, and rehydration ratio of tiger nuts. Among them, the interaction of hot air temperature and hot air humidity had a very significant effect on the drying time and value of chromatism value of tiger nuts, the interaction of hot air temperature and hot air speed had a very significant effect on the hardness of tiger nuts drying, and the interaction of hot air humidity and hot air speed had a very significant effect on the luminosity value.

3) Through data analysis, the technological conditions of hot air drying of tiger nuts were finally determined as follows: hot air temperature $63.15^{\circ} \mathrm{C}$, hot air humidity $44.92 \%$, and hot air wind speed $2.48 \mathrm{~m} / \mathrm{s}$. Under these conditions, the drying time of tiger nut was short, the energy consumption was low, the color was good and the sensory quality was good.

4) By comparing the fatty acid composition and content of tiger nut oil with soybean oil, olive oil, rapeseed oil and sesame oil, we can draw a conclusion: among the saturated fatty acids of tiger nut oil, palm oil has the highest content $(11.172 \%)$, which is between soybean oil and olive oil. Tiger nut oil is rich in 
unsaturated fatty acids. The content of unsaturated fatty acids in tiger nut oil is as high as $86.557 \%$, which is the highest in vegetable oil. The main composition of unsaturated fatty acids in tiger nut oil is oleic acid, with a content of $77.605 \%$, which is 3.6 times higher than that of soybean oil, and even higher than that of olive oil. Therefore, China can strengthen the promotion of tiger nut oil, further study the efficacy and refining methods of tiger nut oil, and formulate the industry standard or national standard of tiger nut oil.

\section{Acknowledgements}

This work was financially supported by the model and demonstration of comprehensive utilization of agricultural facilities based on the increasing income of tobacco farmers in Henan tobacco-growing area (Grant No. 2018410000270095); the Special Project for scientists in the 13th Five-Year Plan of China's Agricultural Research System (CARS-04-PS25).

\section{[References]}

[1] Wang R Y, Wang X S, Xiang H. One kind of multi-purpose novel oil crop - Cyperus beans. China Oils and Fats, 2019; 44(1): 1-4. (in Chinese)

[2] Wang Y X, Wu S X, Zhou L P, Zhang K H, Li P X. Research progress on quality analysis, processing and utilization of Cyperus esculentus. The Food Industry, 2020; 41(10): 273-276. (in Chinese)

[3] Hu B, Zhou K, Liu Y T, Liu A P, Zhang Q, Han G Q, et al. Optimization of microwave-assisted extraction of oil from tiger nut (Cyperus esculentus L.) and its quality evaluation. Industrial Crops and Products, 2018; 115 : 290-297. doi: 10.1016/j.indcrop.2018.02.034

[4] Duan L, Peng Y, Yu H P, Han M, Wu X L. Property analysis and spectral characterization of Cyperus esculeutus oil extracted by different methods. Food Science and Technology, 2020; 45(3): 201-205. (in Chinese)

[5] Liu Y L, Wang Y L, Shu Yao, Ma Y X. Character and composition of Cyperus esculentus from different origins. China Oils and Fats, 2020; 45(8): 125-129. (in Chinese)

[6] Wang L, Zhou G W, Yu Z C, Meng L B, Wang Y Y, Zhang A Q, et al. Effect of $\mathrm{pH}$ shift treatment on structure and emulsifying properties of tiger nut protein. Food Science and Technology, 2020; 41(22): 34-41. (in Chinese)

[7] Zhao Y G, Zhou S Q. China has bred the first high-oil and high-yield tiger nut variety. Agricultural Engineering, 2018; 2: 114-114. (in Chinese)

[8] Huang M H, Wang X H, Pang Z Y. Research status and prospect of Cyperus esculentus. Crop Research, 2013; 27(3): 293-295, 301. (in Chinese)

[9] Zhang X K. Research and development progress report of Cyperus oleifera Industry in China. China Rural Science \& Technology, 2019; 4: 67-69. (in Chinese)

[10] Zhao Y G, Zou X L, Zhang Y, Han Z K, Zeng L, Zhang X K. Tiger nut high oil and high yield variety Zhongyousha 1. China Seed Industry, 2019; 6: 96-97. (in Chinese)

[11] Lu Z Y, Liu H, Zhang J Z, Ren Y F, Cheng Y F, Cheng Y C, et al. Current situation, problems and suggestions of tiger nut industry development. Modern Agriculture, 2019; 6: 11-13. (in Chinese)

[12] Chen X Q, Chen S, Yuan X Z. Effect of membrane permeability of yeast on ethanol production from fermented Yolchia soybean meal. Journal of Basic Science and Engineering, 2009; 17(5): 697-706. (in Chinese)

[13] Tian X L, Zhang G Q. Optimization of oligosaccharide extraction from tiger nut meal by response surface methodology. The Food Industry, 2020; 41(3): 13-16. (in Chinese)

[14] Duan L, Yu H P, Han M. Optimization of supercritical CO2 extraction of tiger nut oil by response surface methodology and analysis of physicochemical properties. The Food Industry, 2020; 41(9): 118-121. (in Chinese)

[15] Tunde-akintunde T Y, Oke M O. Thin-layer drying characteristics of tiger nut (Cyperus esculentus) seeds. Journal of Food Processing and Preservation, 2012; 36(5): 457-464.
[16] Abano E E, Amoah K K. Effect of moisture content on the physical properties of tiger nut (Cyperus esculentus). Asian Journal of Agricultural Research, 2011; 5(1): 56-66.

[17] Usman D D, Ismail A D, Jahun B G, Ibrahim K. Effect of moisture content variation on thermo-physical properties of brown variety Tigernut (Cyperus esculentus). Arid Zone Journal of Engineering, Technology \& Environment, 2016; 1(1): 1-7.

[18] Huang S R, Wu X F, Mi X P, Li J, Liu D W. The invention relates to a method for prolonging the shelf life of peeled yucca bean. CN201611160332.1.2017-05-30. (in Chinese)

[19] Li G, Ji F, Xiang S N. Analytical study on pyrolyzed products of Desmodesmus sp cultivated in BG11. Int J Agric \& Biol Eng, 2017; 10(3): 218-226.

[20] Hurtado D X, Garzon-Castro C J, Cortes-Romero J. Comparison of lipid extraction methods for the microalgae Acutodesmus obliquus. Int J Agric \& Biol Eng, 2018; 11(5): 211-217.

[21] Zhou R, Lei H W, Julson J L. Effects of reaction temperature, time and particle size on switchgrass microwave pyrolysis and reaction kinetics. Int J Agric \& Biol Eng, 2013; 6(1): 53-61.

[22] Li G, Ji F, Bai X. Comparative study on thermal cracking characteristics and bio-oil production from different microalgae using Py-GC/MS. Int J Agric \& Biol Eng, 2019; 12(1): 208-213.

[23] National Health and Family Planning Commission of the People's Republic of China. National standards for food safety. Determination of moisture in foods: GB 5009.3-2016. (in Chinese)

[24] Kha T C, Nguyen M H, Roach P D. Effects of spray drying conditions on the physicochemical and antioxidant properties of the Gac (Momordica cochinchinensis) fruit aril powder. Journal of Food Engineering, 2010; 98(3): 385-392.

[25] Zhang L J. Effect on the quality of tempering on microwave drying soybeans. Tianjin: Tianjin University of Science and Technology, 2017; 61p. (in Chinese)

[26] Qian Q Y, Zhang Q, Wang J, Fang X M, Zhang W P, Gao Z J, et al Effects of three drying technologies on drying characteristics and quality of jujube chips. Transactions of the CSAE, 2016; 32(17): 259-265. (in Chinese)

[27] Li Q H, Fu C L. Application of response surface methodology for extraction optimization of germinant pumpkin seeds protein. Food Chemistry, 2005; 92(4): 701-706.

[28] İbrahim Doymaz. Experimental study on drying of pear slices in a convective dryer. International Journal of Food Science \& Technology, 2013; 48(9): 1909-1915.

[29] GB 5009.168-2016. National food safety standard, Determination of fatty acids in food, 2016. (in Chinese)

[30] Huai X L, Wang L, Ni X Z. Analysis of heat and mass transfer of granular materials during drying. Acta Scientiarum Naturalium Universitatis Pekinensis, 1998; 5: 3-5. (in Chinese)

[31] Wang T, He F, Zhan J, Huo K L, Zhao H W, Wang M, et al. Color parameters and chemical components in different leaf positions of flue-cured tobacco leaves during bulk curing process. Journal of Hunan Agricultural University (Natural Sciences), 2012; 38(2): 125-130. (in Chinese)

[32] Wang T, He F, Zhan J, Li W, Zhao H W, Pei X D, et al. Relationship between appearance change and chemical composition of flue-cured tobacco based on chromaticity and morphology during intensive curing. Journal of Huangzhong Agricultural University, 2013; 31(6): 765-770.

[33] Maskan M. Kinetics of colour change of kiwifruits during hot air and microwave drying. Journal of Food Engineering, 2001; 48(2): 169-175.

[34] Zhu W X. Principle and technology of food drying, 2009. (in Chinese)

[35] Ling Z Z, Ren G Y, Duan X, Li L L, Ma L P, Dong T Y, et al. Optimization and quality study of batch microwave-hot air coupled drying peanut. Food \& Machinery, 2020; 36(10): 183-189. (in Chinese)

[36] İbrahim Doymaz. Hot-air drying and rehydration characteristics of red kidney bean seeds. Chemical Engineering Communications, 2016; 203(5): 599-608.

[37] Bi J, Fang L, Ding Y, Wang P. Optimization of explosion puffing drying for pineapple at variable temperature and pressure difference. Transactions of the CSAE, 2008; 25(10): 334-339.

[38] Nurulain S, Aziz N A, Najib M S, Salim M R, Manap H. A review of free fatty acid determination methods for palm cooking oil. Journal of Physics: Conference Series, 2021; 1921(1): 012055. doi: 10.1088/ 1742-6596/1921/1/012055. 